\title{
Review of regional carbon counting methods for the Chinese major ecological engineering programs
}

\author{
Ji Zheng ${ }^{1}$ Xiaohua $\mathrm{Wei}^{2} \cdot$ Yuanqiu Liu ${ }^{1}$ - Guohua Liu ${ }^{3}$ - Weifeng Wang ${ }^{4}$. \\ Wenfei Liu ${ }^{5}$
}

Received: 1 November 2014 / Accepted: 4 February 2015/Published online: 7 May 2016

(C) Northeast Forestry University and Springer-Verlag Berlin Heidelberg 2016

\begin{abstract}
In order to improve environment and relieve poverty, China has launched a series of major ecological engineering programs since the 1980s. These include the Natural Forest Conservation Program, the Sloping Cropland Conversion Program, the Desertification Combating Program, and the Protection Forest System Construction Program. There is a growing need to quantify the contributions of these programs to regional carbon stocks. However, the lack of widely accepted, robust methods is one of the key obstacles to quantification. The objective of this study was to review existing methods for quantifying
\end{abstract}

Project funding: This research was supported by grants from Strategic Priority Research Program of Chinese Academy of Sciences (No. XDA05060101), Graduate Innovation Project Funding of Jiangxi Province (No. YC2013-S117), Jiangxi Provincial Science and Technology International Cooperation Project (No. 09003614), GanPo 555 Talent Project Funding of Jiangxi Province.

The online version is available at http://www.springerlink.com

Corresponding editor: Hu Yanbo

Xiaohua Wei

adam.wei@ubc.ca

1 College of Forestry, Jiangxi Agricultural University, Nanchang 330045, China

2 University of British Columbia (Okanagan Campus), Kelowna, BC V1V1V7, Canada

3 State Key Laboratory of Urban and Regional Ecology, Research Center for Eco-Environmental Sciences, Beijing 100085, China

4 Inner Mongolia Academy of Forestry Science, Hohhot 010010, China

5 Research Institute of Ecology \& Environmental Sciences, Nanchang Institute of Technology, Nanchang 330099, China regional carbon stocks and then recommend suitable ones for the Chinese ecological engineering programs. We expect that the recommended methods can be applied to elsewhere in the world where there are similar characteristics and objectives.

Keywords Ecological engineering programs · Carbon counting methods $\cdot$ Carbon stocks $\cdot$ Regional scale

\section{Introduction}

Terrestrial forest ecosystems play an important role in global carbon budgets (Pan et al. 2011). However, global forests are undergoing dramatic changes. On one hand, global forests are experiencing growing human influence, climate change impacts and frequent natural disturbance, which has resulted in continuous decline in both forested areas and forest productivity. On the other hand, various countries and regions are implementing reforestation and afforestation programs to deal with severe environmental problems such as soil erosion, loss of wildlife habitat and biodiversity, and decline of watershed functions. These restoration programs increase forest areas in some regions and countries. In either case, there is an important need to quantify the effects of forest changes on forest carbon stocks (Fang et al. 2014) to guide future forest management. Accurate quantification of terrestrial ecosystem carbon pools, carbon sequestration rates and their influencing factors at a regional scale is the basis for constructing national and global carbon budgets, and for determining suitable measures to mitigate climate change impacts. This also helps negotiate fairly between countries in setting carbon emission reduction commitments. Thus, evaluation of carbon counting methods is not only vital to accurately 
estimating the global carbon budget and the influence of potential climate change on terrestrial ecosystems, but it is also the key to fulfilling international conventions.

In order to address wide-spread environmental degradation, China launched a number of major ecological engineering programs since the 1980s. These include the Natural Forest Protection Program, the Grain for Green Program, the Beijing and Tianjin Sandstorm Source Control Program, the Three North and the Yangtze River Basin Shelter Forestation Program and the Grassland Restoration Program. Implementing these large-scale programs not only improves the ecological environment, but also greatly helps local farmers and communities escape poverty in the program regions. Various case studies have demonstrated that these programs have substantially increased forest carbon stocks and sequestration rates at local levels (Chen and Hay 2009; Wei et al. 2014; Wang et al. 2014; Yu et al. 2014). However, there are few studies on quantification of the contributions of those large-scale programs to forest carbon stocks at regional and national levels. Among various factors, the lack of commonly accepted, robust methods is one of the key obstacles to accurate large-scale quantification. Thus, it is critical to identify suitable methods for assessing the contributions of various major ecological programs to regional forest carbon stocks in China.

Researchers have used various methods to quantify regional forest carbon budgets in many world forests. These methods can be broadly classified as inventory-based methods (e.g., Fang et al. 2001; Guo et al. 2010; Berenguer et al. 2014), remote sensing estimation method (e.g., Goetz and Dubayah 2011), simulation method (Feng et al. 2013) and various combinations of these methods (Blackard et al. 2008; Stinson et al. 2011; Baccini et al. 2012; Liu et al. 2012). The selection and application of methods largely depends on the characteristics of forest ecosystems, data availability and research purposes, which suggests that it may be challenging or even impossible to find a common method for all types of forest ecosystems. This is particularly true for China's forests as all major types of world forests can be found there. As China's major ecological and engineering programs involve various vegetation types, wide arrays of topography and climate, and significant complexities, it is critical to conduct a systematic evaluation of existing methods and identify suitable ones for quantitatively assessing regional carbon contributions of those ecological programs. In addition, existing research on carbon counting often focused on either national, global, or small plot scales. Studies at the regional scale are comparatively rare due to the complexity and variety of forest types, and insufficient and inaccurate databases in this middle scale. The objective of this study was to provide an in-depth review of existing methods for quantification of regional forest carbon budgets, and then recommend suitable methods for those ecological programs in China. We expect the identified methods from this review can have global forestry applications.

\section{A global review on forest ecosystem carbon counting methods at the regional scale}

This section provides a brief review of the most often used approaches to forest ecosystem carbon counting, including the inventory-based method, remote sensing, simulation and various combinations of these methods. A brief summary on pros and cons of each approach is provided in Table 1.

\section{Inventory-based method}

Inventory-based counting normally includes the method for estimating vegetation biomass carbon (vegetation biomass inventory method) and the method for counting soil carbon (soil inventory method) (Yu et al. 2011). The vegetation biomass inventory method mainly relies on use of the allometric growth equation (Tang et al. 2000), the IPCC (Intergovernmental Panel on Climate Change) (Luo et al. 2007; IPCC 2003, 2006) and the biomass conversion factor continuous function method (Fang et al. 2001, 2002). The allometric growth equation method, also known as the regression model, is developed using tree diameter at breast height, tree height and biomass data.

The IPCC method is based on the volume-biomass model developed by IPCC. The model is set up using parameters such as forest volume, wood density, biomass conversion factor and ratio of root to stem.

The formula is:

$B_{\text {total }}=V_{\text {total }} \cdot D \cdot B E F \cdot(1+R)$

where $V_{\text {total }}$ is the total volume of a tree species; $D$ is wood density of a tree species; $B E F$ is biomass expansion factor; and $R$ is ratio of root to stem.

Similar to the IPCC method, the biomass conversion factor continuous function method is also a kind of biomass-based method (Fang et al. 2001, 2002). They calculated the relationship between the BEF (biomass expansion factor) and the stand volume for each forest type based on the data of 758 groups of forest biomass and volumes for 21 forest types in China. Here, the term BEF is defined as the ratio of all stand biomass to stem volume.

The formula is:

$$
\begin{aligned}
B_{\text {total }} & =B \cdot A_{\text {total }}=V \cdot B E F \cdot A_{\text {total }}=V \cdot A_{\text {total }} \cdot B E F \\
& =V_{\text {total }} \cdot B E F \\
B E F & =a+\frac{b}{V}
\end{aligned}
$$


Table 1 The major advantages and disadvantages of inventory-based, remote sensing and simulation approaches for estimating forest carbon

\begin{tabular}{clc}
\hline Approach & Advantages & Disadvantage \\
\hline $\begin{array}{c}\text { Inventory- } \\
\text { based }\end{array}$ & Simple and direct; results are normally reliable & $\begin{array}{c}\text { Requiring comprehensive and long-term databases; Concern over data } \\
\text { quality and consistence }\end{array}$ \\
$\begin{array}{c}\text { Remote } \\
\text { sensing }\end{array}$ & $\begin{array}{c}\text { Suitable for estimation and long-term monitoring at large } \\
\text { spatial scales }\end{array}$ & $\begin{array}{c}\text { Lack of accuracy; the problem with saturation of spectral signals; and } \\
\text { high cost with application of active remote sensors }\end{array}$ \\
$\begin{array}{c}\text { Simulation } \\
\text { High efficiency on time and cost; simulating the effects of } \\
\text { various variables and scenarios on carbon }\end{array}$ & $\begin{array}{c}\text { Less reliable; often overparameterizing; and requiring significant and } \\
\text { robust calibration and validation }\end{array}$ \\
\hline
\end{tabular}

where $B$ is unit area biomass of a forest type; $A_{\text {total }}$ is the total area of a forest type; $V$ is unit area volume of a forest type; $V_{\text {total }}$ is total volume of a forest type; and $a$ and $b$ are constants.

Soil carbon inventory methods mainly include the methods based on soil types, vegetation types and life zones. The method based on soil types (Wang et al. 2003; Li et al. 2007) calculates soil carbon storage of each soil type in each unit, and then estimates total soil carbon according to the total area of each soil type on the regional or national scale soil maps. The method based on vegetation types and life zones (Wang et al. 2003; Li et al. 2007) calculates soil carbon storage by sampled carbon density and the area of each vegetation type, life zone or ecosystem type. This method can directly reflect soil carbon of different vegetation types, life zones or ecosystem types.

Estimating the vegetation carbon pool is more complicated than estimating the soil carbon pool. The tree layer carbon pool is the main part of the vegetation carbon pool, and accurate estimation of tree layer carbon is the key for estimating vegetation carbon. Estimation of the tree layer biomass can be done with the allometric growth equation or the volume and biomass conversion factor. In either case, accuracy of the equation and the biomass conversion factor for tree species are the key for accurately estimating the vegetation carbon pool. In addition, estimates of underground vegetation carbon storage (in root systems) are not easy to calculate, so the ratio of above- to belowground biomass is often used in spite of its unknown level of uncertainty. In contrast, the accuracy of soil bulk density, thickness and soil carbon density is the key for accurate estimation of soil carbon pool in each forest type.

The inventory-based method is widely used at regional and national scales (Kern 1994; Bernoux et al. 2002; Schwartz and Namri 2002; Krogh et al. 2003; Yu et al. 2005; Chaplot et al. 2010; Fang et al. 2007). For example, Fang et al. (2007) used forest resources inventory data with the biomass conversion factor continuous function to estimate China's terrestrial ecosystem vegetation carbon storage in 1981-2000. In estimating soil carbon storage, Zhi et al. (2013) used the 1:50,000 soil database of Zhejiang province to estimate soil organic carbon densities of 277 soil types. The inventory-based method is relatively simple and direct, and can be used to calculate vegetation carbon at different spatial scales with clear separation of different components of forest ecosystem carbon. The disadvantage of the method is that it requires data accumulated over many years and its accuracy is largely dependent upon data quality.

\section{Remote sensing method}

Remote sensing method refers to the use of remote sensing data from airborne or spaceborne sensors in estimation of forest carbon variables. Spatial resolutions of images and sampling frequency determine data precision and application. A brief summary of major passive and active remote sensors and their applications is provided in Tables 2 and 3 (from Guo et al. 2014), respectively.

Applications of remote sensing in forestry are mainly concentrated in measuring forest area, tree height, leaf area index, crown canopy width and classifying forest types. With remote sensing data, statistical methods and simulations can be applied to estimate forest aboveground biomass and carbon. For example, a statistical method is normally used to establish the relationship between biomass variables and the reflectance spectrum of vegetation in the remote-sensing images. This relationship is then used to inversely calculate biomass and carbon. Depending on types of remote sensing data, the relationship can be established between the reflection value of TM image data in the optical remote sensing (the vegetation index) and ground survey biomass data (Curran and Steven 1983; Sellers 1985; Sader et al. 1989) or between the spectral signal of SPOT data and forest stand biomass (Trotter et al. 1997). When the correlation between biomass and remote sensing variables is not so significant, a neural network model is often used to obtain a more reliable correlation (Foody et al. 2001). In addition, remote sensing data can be used to macroscopically and continuously monitor vegetation biomass changes with sufficiently high spatial resolutions. However, the problem with saturation of remote sensing spectral signals causes possible large errors in estimating forest biomass and carbon when forests reach a level of maturity (Hyde et al. 2007; Huang et al. 2012a, b; Tang et al. 2012). 
Table 2 The major passive remote sensors and their applications on forest biomass estimation

\begin{tabular}{llll}
\hline Sensor type & Image resolution & $\begin{array}{l}\text { Sampling } \\
\text { frequency (day) }\end{array}$ & Applications on forestry \\
\hline $\begin{array}{l}\text { TM/ETM+ } \\
\text { MODIS }\end{array}$ & $30 \mathrm{~m} \mathrm{(ETM} \mathrm{all} \mathrm{band} 15 \mathrm{~m})$ & 16 & $\begin{array}{l}\text { Forest classification and detection of forest area changes } \\
\text { Forest classification and calculation of NDVI, LAI and NPP at a } \\
\text { coarse resolution }\end{array}$ \\
SPOT & $250-1000 \mathrm{~m}$ & $1-2$ & $\begin{array}{l}\text { Accurate measurement of main characteristics of vegetation } \\
\text { Accurate measurement of main characteristics of vegetation }\end{array}$ \\
IKONOS & $4 \mathrm{~m}($ all band $1 \mathrm{~m})$ & 26 & $\begin{array}{l}\text { Accurate measurement of main characteristics of vegetation } \\
\text { QuickBird }\end{array}$ \\
\hline
\end{tabular}

Table 3 The active remote sensors and their applications on forest biomass estimation

\begin{tabular}{|c|c|c|c|c|c|}
\hline Type & Height & Spot size & Precision & Application scale & Application on forestry \\
\hline Terrestrial LiDAR & $1 \mathrm{~m}$ & $0.5-10 \mathrm{~cm}$ & $1-10 \mathrm{~cm}$ & Single tree-stand & $\begin{array}{l}\text { Tree height, diameter at breast height, leaf } \\
\text { area index etc. }\end{array}$ \\
\hline Airborne LiDAR (small plot) & $1 \mathrm{~km}$ & $0.2-3 \mathrm{~cm}$ & $0-20 \mathrm{~cm}$ & \multirow[t]{2}{*}{ Landscape-region } & \multirow{2}{*}{$\begin{array}{l}\text { Distribution of tree height, coverage, leaf } \\
\text { area index, volume and biomass estimation } \\
\text { in landscapes or regions }\end{array}$} \\
\hline Airborne LiDAR (big plot) & $10 \mathrm{~km}$ & $8-25 \mathrm{~m}$ & $\begin{array}{l}\text { Bare land } 50 \mathrm{~cm} ; \\
\text { Vegetation } 100 \mathrm{~cm}\end{array}$ & & \\
\hline Satellite LiDAR & $600 \mathrm{~km}$ & $60-70 \mathrm{~m}$ & $5-10 \mathrm{~m}$ & Region-global & $\begin{array}{l}\text { Global tree height distribution, biomass } \\
\text { estimation }\end{array}$ \\
\hline
\end{tabular}

Laser radar (LiDAR) not only overcomes the saturation problem of optical signals, but also provides more abundant vertical structure information of forests (e.g., canopy height). Such information is closely related to forest stand volumes and biomass (Lim et al. 2003), and has also been utilized by various researchers (e.g., Chen 1999) to derive forest biomass. For example, Chen and Hay (2009) utilized the height information obtained from LiDAR profiles and the ground feature information obtained from Quickbird images to extract continuous regional data with extremely high precision for estimation of regional biomass. Baccini et al. (2012) utilized the combination of GLAS (Satellite LiDAR) with MODIS data to develop forest vegetation carbon density maps in the pan-tropical zone. Huang et al. (2013) adopted data from airborne and satellite-borne laser radars to estimate forest biomass within the range of GLAS spot, and then combined MODIS vegetation products and MERIS land covering products to develop the continuous maps of forest biomass in Yunnan province. LiDAR does, however, achieve limited penetration through heavy fog and this increases uncertainty in estimates of forest biomass and carbon.

In summary, remote sensing data from passive sensors can be better used to classify major vegetation types and measure vegetation characteristics, which can be further combined with inventory and sampling data for estimating forest carbon, while remote sensing data from active sensors can be better applied to estimate forest biomass and stocks of various forest types, which can then be totaled to estimate regional forest carbon.

\section{Simulation method}

There are various simulation models for estimating forest carbon at the regional scale (Table 4). According to the data types used for model calibration, these models may be classified as inventory data-based (Smith and Heath 2001; Richards and Evans 2000; Kurz et al. 2009; Stinson et al. 2011; Masera et al. 2003) and remote sense data-based simulation models (Smith et al. 2008). This section briefly introduces these two categories of simulation models. In addition, some models may incorporate both inventory and remotely sensed data for improved simulations.

\section{Simulations based on sampling and inventory data}

Various models have been developed to use sampling and inventory data. These models vary in terms of application scales, geographic areas, forest management, required parameters and precisions. Examples of these models include the FORCARB model from USA (Smith and Heath 2001), CAMfor model from Australia (Richards and Evans 2000), CBM-CFS3 model from Canada (Kurz et al. 2009; Stinson et al. 2011), and $\mathrm{CO}_{2} \mathrm{FIX}$ model of V3 version (Masera et al. 2003). Each model has its own strengths and weaknesses. For example, the CBM-CFS3 model has been 
Table 4 Comparison of the major forest carbon models

\begin{tabular}{|c|c|c|c|c|c|c|c|c|c|}
\hline \multirow[t]{2}{*}{ Model } & \multirow[t]{2}{*}{ Feature } & \multicolumn{7}{|c|}{ Application } & \multirow[t]{2}{*}{ Reference } \\
\hline & & $\begin{array}{l}\text { Regional } \\
\text { scale }\end{array}$ & $\begin{array}{l}\text { Forest } \\
\text { stand } \\
\text { scale }\end{array}$ & $\begin{array}{l}\text { Natural } \\
\text { forest }\end{array}$ & $\begin{array}{l}\text { Managed } \\
\text { forest }\end{array}$ & Grassland & $\begin{array}{l}\text { Vegetation } \\
\text { carbon } \\
\text { pool }\end{array}$ & $\begin{array}{l}\text { Soil } \\
\text { carbon } \\
\text { pool }\end{array}$ & \\
\hline $\mathrm{CO}_{2} \mathrm{FIX}$ & $\begin{array}{l}\text { Simulating carbon } \\
\text { dynamics of a single tree } \\
\text { species and multiple tree } \\
\text { species in different age } \\
\text { class stands and } \\
\text { agroforestry }\end{array}$ & $*$ & $*$ & $*$ & $*$ & - & $*$ & $*$ & $\begin{array}{l}\text { Masera et al. } \\
\text { (2003) }\end{array}$ \\
\hline CENTURY & $\begin{array}{l}\text { Simulating long-term } \\
\text { dynamics of } \mathrm{C}, \mathrm{N}, \mathrm{P}, \mathrm{S} \text { in } \\
\text { different soil systems }\end{array}$ & $*$ & - & $*$ & $*$ & $*$ & $*$ & $*$ & $\begin{array}{l}\text { Parton et al. } \\
\quad(1987,1993)\end{array}$ \\
\hline FORECAST & $\begin{array}{l}\text { Simulating carbon } \\
\text { dynamics of a single tree } \\
\text { species and multiple tree } \\
\text { species at the forest stand } \\
\text { level }\end{array}$ & - & $*$ & $*$ & $*$ & - & $*$ & $*$ & $\begin{array}{l}\text { Wei and Blanco } \\
\text { (2014) }\end{array}$ \\
\hline CBM-CFS3 & $\begin{array}{l}\text { Forest management and the } \\
\text { effects on forest carbon } \\
\text { and changes }\end{array}$ & $*$ & $*$ & $*$ & $*$ & - & $*$ & $*$ & $\begin{array}{l}\text { Kurz et al. } \\
\text { (2009) }\end{array}$ \\
\hline TRIPLEX & $\begin{array}{l}\text { Simulating monthly forest } \\
\text { biomass production }\end{array}$ & $*$ & * & - & $*$ & - & $*$ & $*$ & $\begin{array}{l}\text { Peng et al. } \\
\text { (2002), Zhang } \\
\text { et al. (2008) }\end{array}$ \\
\hline Miami & $\begin{array}{l}\text { Predicting NPP of different } \\
\text { areas with annual } \\
\text { average temperature, } \\
\text { precipitation and soil } \\
\text { moisture }\end{array}$ & $*$ & - & $*$ & $*$ & $*$ & $*$ & - & $\begin{array}{l}\text { Adams et al. } \\
\text { (2004) }\end{array}$ \\
\hline CASA & $\begin{array}{l}\text { Simulating large scale NPP } \\
\text { based on the plant } \\
\text { processes mechanisms }\end{array}$ & $*$ & - & $*$ & $*$ & $*$ & $*$ & - & $\begin{array}{l}\text { Potter et al. } \\
\text { (1993) }\end{array}$ \\
\hline $\begin{array}{l}\text { BIOME- } \\
\text { BGC }\end{array}$ & $\begin{array}{l}\text { Simulating the storage and } \\
\text { flux of water, carbon and } \\
\text { nitrogen of ecosystem } \\
\text { vegetation, litter and soil } \\
\text { in regional or global } \\
\text { scales }\end{array}$ & $*$ & - & $*$ & $*$ & $*$ & $*$ & $*$ & $\begin{array}{l}\text { Running and } \\
\text { Gower (1991) }\end{array}$ \\
\hline BEPS & $\begin{array}{l}\text { Simulating GPP and NPP } \\
\text { at the daily interval } \\
\text { considering shade and } \\
\text { sunny leaves }\end{array}$ & $*$ & - & $*$ & $*$ & $*$ & $*$ & - & Liu et al. (1997) \\
\hline
\end{tabular}

* Represent YES, - represent NO)

extensively applied to simulate forest carbon sequestration under varying forest management regimes at the regional scale, but it cannot simulate the impacts of climatic variability on carbon stocks. Another widely applied model, $\mathrm{CO}_{2}$ FIX model can be adopted to simulate the carbon dynamics of forest stands and agroforestry with a single tree species or multiple tree species at different ages, but it relies excessively on the tree trunk growth rate, and cannot reflect the changes arising from the geographic and climate variations.

\section{Simulations based on remote sensing data}

Many ecosystem carbon models adopt remote sensing data as their model parameters or driving variables to calculate forest ecosystem carbon. There are three categories of this kind of model (Smith et al. 2008). The first one is climate models, such as the Miami model (Adams et al. 2004), which predicts NPP using parameters such as soil moisture, precipitation and annual average temperature, but neglects the biological properties of plants themselves. The models 
are now mainly used to compare with simulation results of other models. The second type is physiological models, such as BIOME-BGC model (Running and Gower 1991) and BEPS model (Liu et al. 1997). For example, the BIOME-BGC model takes environment factors as the variables, and combines biochemical reaction mechanisms of plant photosynthesis based on the soil moisture information and vegetation coverage, and can simulate vegetation, litters of ecosystems of different scales, water, carbon, and nitrogen stocks and fluxes, but its application is restricted by the complexity of its parameters. Third type is the solar energy utilization efficiency models, such as the CASA model (Potter et al. 1993), which utilizes the relation between NPP and the photosynthetically active radiation (PAR) absorbed by plants to estimate NPP. The inputted parameters such as PAR proportion can be obtained through remote sensing rather than field sampling. The models are quite simple in their form, and consider more the characteristics of environmental condition and vegetation than climate models. All three types of models need remote sensing data sources of high time resolution when estimating ground biomass. The spatial resolution of remote sensing data sources is, however, generally low and this reduces land cover classification precision and introduces a level of uncertainty when estimating NPP.

\section{Methods recommended for assessing the contributions of China's major ecological engineering programs to regional carbon budgets}

According to the similarity of the purposes and activities in the six major ecological engineering programs, we grouped the Natural Forest Conservation Program, The Three North Shelterbelt Development Program and The Yangtze River and Pearl River Basin Shelter Forest Program into one category. The Sloping Cropland Conversion Program and Grazing for Grass Program were assigned to the other two categories. In addition, the carbon evaluation method from the latter two categories can be used for the Beijing-Tianjin Wind and Sand Source Control Program. Thus, our review focused on three programs including Sloping Cropland Conversion Program, Natural Forest Conservation Program and Grazing for Grass Program.

\section{Sloping Cropland Conversion Program}

\section{Introduction}

In the Sloping Cropland Conversion Program, steeply sloping lands that are susceptible to serious water loss and soil erosion, sand storms, and other natural events are restored to woodlands. Afforestation and seeding measures are taken to form stable forest ecological systems so that environmental deteriorating trends can be halted. The Program focuses on steep farmlands at both banks of rivers and around lakes and reservoirs as well as desertized farmlands in sandstorm areas. The implementation areas of this Program include a total of 1897 counties (including cities, districts and prefectures) in 25 provinces and the Xinjiang Production and Construction Corps. The key objectives and milestones of this Program are: (i) by 2010 , afforesting $1.47 \times 10^{7}$ ha of abandoned farmlands and $1.73 \times 10^{7}$ ha of waste mountains and lands (both categories of afforestation interact with the Grain for Green Program from 1999 to 2000); (ii) restoring grain croplands to forests on steep slopes; and (iii) increasing forest coverage by $4.5 \%$ in the Program regions ( $\mathrm{Li} 2005$ ). Currently, Phase II of this Program is under planning.

\section{Features and challenges in carbon counting}

Three categories of measures are implemented in this Program: afforestation of abandoned farmland, afforestation of waste mountains, and closing hills for reforestation. Each measure employs plant species suited to given geographical locations, weather conditions, and other factors in the program areas. For instance, different proportions of mixed broadleaf-conifer forests, and arbor-shrub-grass mixtures are applied to promote long-term ecological recovery in sub-tropic regions of southern China, while walnut (Juglans regia), oil camellia (Camellia oleifera), and other varieties of cash trees are planted to promote short-term economic benefits in other program areas. Applications of different species impose some challenges in carbon counting as each tree species may have unique features that require consideration.

Another challenge is that program implementation areas are geographically scattered or sometimes overlap (e.g., Beijing-Tianjin Wind and Sand Source Control Program). This leads to difficulty in applying remote sensing images to determine the spatial boundaries for each program.

At present, the program is concentrated on the Loess Plateau and has defined afforestation patterns that are amenable to remote sensing interpretation and extraction of vegetation indices. Thus, the combination of remote sensing with modeling can be considered for estimating carbon stocks in this region. In addition, the program is implemented at the county level. As a result, data are normally summarized at the county level, suggesting that forest carbon budgets at the regional or national levels can be summed up from the county level estimates.

\section{Recommended methods}

Based on data availability, program purposes and unique features, we recommend the allometric equation method 
for estimating carbon stocks of aboveground vegetation. Using data from sampling plots and the literature to establish allometric equations of representative tree species in different regions, the method can be used across the entire country. In addition, the Loess Plateau is a priority region for program implementation. In this region, distribution areas are generally concentrated with fixed afforestation patterns and arrangements. Thus, it is possible and effective to use remote sensing data to develop various vegetation indices, which then can be used to drive suitable models. We found that the CASA model proved most effective for the Loess Plateau region (see Feng et al. 2013) and we recommend its use for estimating aboveground vegetation NPP and carbon storage. We recommend the CENTURY model for estimating soil carbon stocks. The CENTURY model has been widely used for estimating soil carbon fluxes and stocks (Parton et al. 1987, 1993). The CENTURY model is recommended here because of data availability and in light of the research purposes of the Ecological Engineering Programs.

\section{The allometric growth equation method}

According to dominant tree species, we first place DBH and tree heights into different groups, and then apply biomass allometric equations that correspond to tree species to calculate total biomass of a single plant from sampling plots. Using carbon contents of each tree organ (stem, branch, leaf, root), we then convert biomass into carbon storage. Total carbon storage of the arborous layer in the plots can be obtained by summing carbon stored in all tree species in sampling plots, while the carbon storage per unit area can be calculated by dividing by the total area of the sample plots. Using the data from the sampling plots, carbon storage can be calculated per unit area for undergrowth vegetation layers, litter layers (litter and fallen dead wood) and soils. By summing carbon storages or pools of the arborous layer, undergrowth vegetation, litter and soils, we can obtain total carbon storage and density for any sampling plot. Average carbon density of each forest type at different ages in each province or region can be then estimated based on the number of sampling plots. Finally, total forest carbon storage can be derived from average carbon densities of the forest types, ages and corresponding implementation areas. The basic formula (Eq. 4) is described as below.

$C_{F}=\sum_{k=1}^{K} \sum_{i=1}^{I} \sum_{j=1}^{J}\left(C_{F_{i, j, k}} \times A_{F_{i, j, k}}\right)$

where $C_{F_{i, j}}$ is forest ecosystem carbon storage per unit area at forest age $j$ of forest type $i$ in province $k\left(\mathrm{t} \mathrm{Cha}^{-1}\right)$; and
$A_{F_{i, j, k}}$ is area at forest age $j$ of forest type $i$ in province $k$ (ha).

To implement this method it is necessary to compile data from sampling plots (for establishing biomass allometric equations) along with forest inventory data, remote sensing data (China Cover) and project implementation plans at each implement period. The potential errors may be associated with establishment of allometric growth equations and accurate information regarding implementation areas and forest types.

\section{CASA-CENTURY modeling method}

The remote sensing-driven CASA model can be used to estimate carbon stocks of aboveground vegetation, while the CENTURY model is for soil carbon. To apply the CASA model, firstly, it is necessary to collect MODIS NDVI data at $1 \mathrm{~km}$ resolution for the modeling area, monthly average rainfall data, temperature data, total solar radiation data, and maps of soil textures and vegetation. Secondly, gridded or rasterized data on climate, soil and vegetation are produced to match the formats of remote sensing data over space. Thirdly, the calculated annual primary productivity of the vegetation types are multiplied by the number of project implementation years to derive carbon densities of aboveground vegetation. Finally, estimates of the forest carbon densities and the project areas are used to estimate carbon storage of aboveground vegetation. Because the CASA model can only simulate NPP of aboveground vegetation, it cannot be used alone. In addition, it is difficult to determine the values of maximum light conversion rates of global vegetation, which may have significant impacts on NPP estimation. The model also needs remote sensing data of high time resolution for estimating above-ground biomass but the spatial resolution is generally low for remote sensing data sources with high time resolution and mixed pixels in images can reduce accuracy of land cover classification. All these factors can introduce errors into NPP estimation.

To apply the CENTURY model to estimate soil carbon storage, we need climate and soil data such as monthly average rainfall, the highest and lowest temperature, soil structure, original contents of total sulphur, nitrogen and phosphorus of soils and data on soil erosion. Secondly, land-use types must be defined, and input data must be parameterized for model calibration. These parameters include soil specific weight, the number of soil layers in a soil profile, drainage patterns, permanent wilting point of soil and PH value in Module 1; and active organic carbon, non-active organic carbon, carbon/nitrogen ratio of each soil layer, initial input of plant detritus, carbon/nitrogen ratio in soil litter, carbon/nitrogen ratio of the soil organic 
horizon and quantity of $\mathrm{C}$ isotope of soil litter in Module 2. Thirdly, the simulations are conducted to calculate soil carbon density in the model area. Finally, total soil carbon storage is estimated from soil carbon densities and the areas of the project regions. Several uncertainties exist when applying this method. It is difficult to obtain some input parameters particularly long-term data series for calibration of the CENTURY model. Additionally, error propagation of the model itself also brings uncertainty. To reduce these potential errors, it is essential to implement quality checks on input data and conduct rigor model validations prior to any simulations.

\section{Natural Forest Conservation Program}

\section{Introduction}

In 1998, China launched the Natural Forest Conservation Program in response to the increasingly deteriorating environment. The fundamental objective of this Program is to stop reduction of natural forests, promote protection, cultivation and development of natural forests, improve the environment, and meet the needs of social and national economic development for forest products through reclassification and zoning of natural forests. The Natural Forest Conservation Program substantially reduced timber production from key state-owned forests in the upper reaches of the Yangtze River, the upper and middle reaches of the Yellow River, northeastern regions, and Inner Mongolia. The objective of these measures was to limit commercial harvest of natural forests in those areas so that afforestation and reforestation could be promoted.

In total, 17 provinces (municipalities) are involved in this Protection Program, including: northeast China, Inner Mongolia, and other state-owned forest zones in Jilin, Heilongjiang, Hainan, Xinjiang, and eastern Inner Mongolia; the upper reaches of the Yangtze River involving Hubei, Chongqing, Sichuan, Guizhou, Yunnan, and Tibet; and the upper and middle reaches of the Yellow River involving Henan, Shaanxi, Shanxi, Inner Mongolia, Ningxia, Gansu, and Qinghai. The Protection Program covers an area of $7.33 \times 10^{6}$ ha of natural forests, accounting for $69 \%$ of China's total natural forest area (Huang et al. 2012a, b). Currently, the Protection Project enters into Phase II.

\section{Features and challenges considered in carbon counting}

In this project, forested lands are divided into two categories: ecological forests and commercial forests. In ecological forests, there are two sub-categories: priority ecological forests and general ecological forests. Forest cutting is prohibited in priority ecological forests, while moderate selective cutting and spacing cutting are allowed in general ecological forests. Commercial forests are mainly used for production of timber. Ecological forests are constructed by forest plantation, aerial seeding and afforestation, mountain closure for reforestation and other methods, while commercial forests are managed for timber production. For example, directed breeding is used for fastgrowing high-yield and economic forests with relatively short rotation lengths. Incremental and sanitation cuttings are strictly implemented in commercial forests.

The age group structures of forests in the program areas (northeast China, Inner Mongolia, and other key stateowned forest zones, the upper Yangtze River, and the upper and middle Yellow River) are characterized by greater proportions of younger to middle-aged forests and fewer mature to overmature forests. In most program areas, not all forested lands belong to the program. In addition, there are no unified maps to specify the boundaries of the program area throughout the country. Currently, the statistical data are based on the program implementation unit (county or city), which is relatively coarse.

\section{Recommended methods}

In theory, it is logical to have different methods for ecological and commercial forests. However, because of the difficult of separating the two categories based on our data, it is impossible to apply different methods according to the forest types. Based on the characteristics of this program as well as data availability, we recommend three methods, CBM-CFS3, remote sensing downscaling method (Liu et al. 2012) and a relatively coarse method, such as the IPCC method or conversion factor continuous function method. Inclusion of the IPCC method or conversion factor continuous function method is mainly because allometric equations are unlikely available for all key species in the program areas. However, when this method is chosen, different methods should be considered for other carbon pools such as soil carbon.

\section{The CBM-CFS3 model method}

The CBM model method is briefly described here. First, according to forest inventory data, we must develop growth and yield curves for key species. Second, we obtain important model parameters such as transfer functions of stand volume-aboveground biomass and litter decomposition rates for modeling areas using published studies and literature. Thirdly, we collect disturbance data and define disturbance and harvesting scenarios. Finally, we run the model to derive carbon densities of aboveground biomass, dead standing trees, underground biomass and soil. To calculate carbon storage of each forest type, apply carbon 
density data with its implementation area, and then sum estimates for all forest types to get total forest storage for a study region.

The combination of different modules with growth and yield curves in the CBM-CFS3 can reduce modeling complexity, but it still has several shortcomings. The model was developed in Canada, so it may work the best for boreal and temperate forests where wildfire disturbance is common. This suggests that application of this model in other forests (e.g., tropic or sub-tropic forests) may require re-setting of growth parameters and corresponding moisture and temperature parameters. Moreover, the model has limited capacity for simulating soil carbon processes and storages, indicating that soil carbon may require separate calculation using other methods.

\section{Remote sensing downscaling method}

First, we use the Chinese vegetation map $(1: 1,000,000)$ to reclassify all forests into three major categories or classes (coniferous, broad-leaved or mixed forest). Meanwhile, we regroup dominant tree species in the forest inventory data into the same three major classes. Second, for three major classes in the forest inventory data, we apply the conversion factor continuous function method to estimate separate averages for biomass. Then, we combine the obtained average biomass of forest vegetation with the reclassified forest vegetation map to generate a distribution map of the average biomass of the three classes. Third, we develop the grid map (1 km resolution) of NPP distribution from remote sensing application, and then overlay it with the distribution map of estimated average biomass to downscale NPP at a regional scale. Finally, we calculate total carbon storage using areal data and data on downscaled NPP spatial distribution.

The basic formula is described as below:

$B_{i}=\frac{N_{i} \times n \times \overline{B_{p t}}}{\sum_{i \in p \cap t} N_{i}}$

where $p$ represent province; $t$ represents forest type (coniferous forest, broad-leaved forest and mixed forest); $i$ represents one grid; $\overline{B_{p t}}$ represents average biomass of one forest type in one province $(\mathrm{Mg} / \mathrm{ha}) ; N_{i}$ represents NPP in one grid $\left(\mathrm{gC} \mathrm{m}^{-2} \mathrm{a}^{-1}\right) ; B_{i}$ represents biomass in one grid $(\mathrm{Mg} / \mathrm{ha})$ and $n$ represents the amount of grids of all forest types in one province.

The required data include a Chinese vegetation map of 1:1,000,000, forest inventory, MODIS NPP/GPP, remote sensing (China Cover) and project implementation areas at each period. Errors may arise from two sources: (1) forest inventory data do not completely match with dominant tree species in the forest vegetation map; and (2) the downscaling formula is established on the basis that forest biomass has positive linear correlation with NPP. However, this is not a correct assumption as NPP is affected by many factors.

\section{IPCC method/conversion factor continuous function method}

Based on forest inventory data, the carbon density of the arborous layer of different forest types is estimated using the IPCC method/conversion factor continuous function method. We use the ratios of above-ground to belowground carbon densities obtained from published studies to estimate carbon densities of other carbon pools so that total carbon density of the forest ecosystem can be calculated. Then, we estimate program implementation areas according to remote sensing data. Finally, we multiply average carbon density of the ecological system with different types and ages and corresponding areas to estimate total carbon storage.

The basic formula is described as below:

$C_{F}=\sum_{k=1}^{K} \sum_{i=1}^{I}\left(C_{F_{i, k}} \times A_{F_{i, k}}\right)$

where $C_{F_{i, k}}$ is forest ecosystem carbon storage per unit area at of forest type $i$ in province $k\left(\mathrm{t} \mathrm{Cha}^{-1}\right)$; and $A_{F_{i, k}}$ is area of forest type $i$ in province $k$ (ha).

The required data include sampling data, forest inventory, remote sensing (China Cover), program implementation areas at each period, wood density and various conversion ratios. Possible errors may arise from two sources: (1) estimation of tree layer carbon using IPCC method/biomass conversion factor continuous function method; and (2) potential uncertainties in application of carbon conversion factors or ratios.

\section{Grazing for Grass Program}

\section{Introduction}

In order to recover degraded grasslands and protect their ecological environment, China began to implement the Grazing for Grass Program in 2003. The program covers Inner Mongolia, Sichuan, Yunnan, Tibet, Qinghai, Gansu, Ningxia, Xinjiang, the Xinjiang Corps, and other regions. The grassland environment is recovered and improved through measures such as fence construction, zoning rotational grazing, rest grazing, banning of grazing, and enriched seeding. By 2010, fences were constructed encompassing a total of $5.2 \times 10^{7}$ ha of grasslands and about $1.24 \times 10^{7}$ ha of severely degraded grasslands were reseeded, resulting in significant improvement in the 
program areas. According to monitoring results from the Ministry of Agriculture in 2010, the average vegetation coverage was $71 \%$ in the program areas, $12 \%$ higher than that in non-program areas. Improvement of different degrees was also made to biological diversity, community structures, and contents of soil organic matter. Moreover, further enhancement was achieved for relevant ecological functions of grasslands, including water conservation and reduction of water loss and soil erosion.

\section{Features and challenges in project carbon counting}

The program includes banning of grazing, resting of grazing and zoning rotational grazing. It is challenging to use remote sensing images to classify the program area as there is little difference between inside and outside of fences. In the grassland ecosystem, soil carbon storage usually accounts for a great proportion of total carbon storage, thus accurate estimation of soil carbon stock is critical for assessment of carbon pools of grasslands (Post et al. 1982, 1990; Ni 2001).

\section{Recommended methods}

Grassland ecosystems are relatively simple and uniform, and the soil carbon pool is the most important component of the total carbon budget. By obtaining the program implementation area, a classification map of grassland, and MODISITM remote sensing image data, we can use GIS to draw a distribution map about the program containing distribution area of each major grassland type. To estimate soil carbon storage of each grassland type, using the CENTURY model with sample plots data is a good choice. Additionally, carbon stock of aboveground vegetation in grassland ecosystems can be obtained by using the CASA model to generate NPP. Detailed descriptions of the CENTURY and CASA models are presented in earlier sections. Thus, remote sensing or modeling combined with CENTURY is recommended for this Program.

\section{Conclusions and uncertainty}

According to the individual characteristics of the major ecological programs, the allometric equation method and the CASA-CENTURY model are recommended for the Sloping Cropland Conversion Program. While the IPCC method and the conversion factor continuous function method based on inventory data of forest resources are recommended for the Natural Forest Protection Program, the CBM-CFS3 model is recommended for commercial forests and the remote sensing downscaling method is for ecological public-welfare forests in the Protection Program. For the Grazing for Grass Program, a combination of remote sensing or remote sensing-based modeling (CASA) with the CENTURY model is recommended.

Several important uncertainties need mentioning here. First, data on the program implementation areas for each key forest type and functional group (e.g., ecological and commercial forests in the Natural Forest Conversion Program) may not be accurate and in some cases are not even available. This could greatly constrain application of allometric growth equations or other recommended methods. In some regions, different programs might overlap, which can lead to overestimation or underestimation of forest carbon stock. Second, a common concern is the general lack of spatially explicit data, which may cause large uncertainties in estimation of soil carbon stock as various soil property data even in each forest type are needed to calculate spatially-based soil carbon. Third, as explained in the text, a perfect method does not exist for estimating forest carbon at the regional scale, and each recommended method has pros and cons. To overcome possible uncertainties in association with the method selection, it is important to apply two complementary methods for each program.

\section{References}

Adams B, White A, Lenton TM (2004) An analysis of some diverse approaches to modelling terrestrial net primary productivity. Ecol Model 177(3):353-391

Baccini A, Goetz SJ, Walker WS, Laporte NT, Sun M, Sulla-Menashe D, Hackler J, Beck PSA, Dubayah D, Friedl MA, Samanta S, Houghton RA (2012) Estimated carbon dioxide emissions from tropical deforestation improved by carbon-density maps. Nat Clim Chang 2(3):182-185

Berenguer E, Ferreira J, Gardner TA, Aragão LEOC, De Camargo PB, Cerri CE, Durigan M, De Oliveira Junior RC, Vieira ICG, Barlow J (2014) A large-scale field assessment of carbon stocks in human-modified tropical forests. Glob Chang Biol 20(12):3713-3726

Bernoux M, Eschenbrenner V, Cerri CC, Melillo JM, Feller C (2002) LULUCF-based CDM: too much ado for a small carbon market. Clim Policy 2(4):379-385

Blackard JA, Finco MV, Helmer EH, Holden GR, Hoppus ML, Jacobs DM, Lister AJ, Moisen GG, Nelson MD, Riemann R, Ruefenacht B, Salajanu D, Weyermann DL, Winterberger KC, Brandeis TJ, Czaplewski RL, McRoberts RE, Patterson PL, Tymcio RP (2008) Mapping US forest biomass using nationwide forest inventory data and moderate resolution information. Remote Sens Environ 112(4):1658-1677

Chaplot V, Bouahom B, Valentin C (2010) Soil organic carbon stocks in Laos: spatial variations and controlling factors. Glob Chang Biol 16(4):1380-1393

Chen EX (1999) Development of forest biomass estimation using SAR data. World For Res 12(6):18-23 (in Chinese)

Chen G, Hay G (2009) Modeling large-area canopy surface heights from lidar transects and quickbird data. Proceedings SilviLaser: College Station, Texas, pp 202-209

Curran P, Steven M (1983) Multispectral remote sensing for the estimation of green leaf area index [and discussion]. Philos Trans R Soc Lond Ser A 309(1508):257-270 
Fang JY, Chen AP, Peng CH, Zhao SQ, Ci LJ (2001) Changes in forest biomass carbon storage in China between 1949 and 1998. Science 292(5525):2320-2322

Fang JY, Chen AP, Zhao SQ, Ci LJ (2002) Estimating biomass carbon of China's forests: supplementary notes on report published in Science (291: 2320-2322) by Fang et al. (2001). Acta Phytoecol Sin 26(2):243-249 in Chinese

Fang JY, Guo ZD, Piao SL, Chen AP (2007) Terrestrial vegetation carbon sinks in China, 1981-2000. Sci China Ser D 50(9):1341-1350 (in Chinese)

Fang JY, Guo ZD, Hu HF, Kato T, Muraoka H, Son YH (2014) Forest biomass carbon sinks in East Asia, with special reference to the relative contributions of forest expansion and forest growth. Glob Chang Biol 20(6):2019-2030

Feng XM, Fu BJ, Lu N, Zeng Y, Wu BF (2013) How ecological restoration alters ecosystem services: an analysis of carbon sequestration in China's Loess Plateau. Sci Rep 3:2846. doi:10. 1038/srep02846

Foody GM, Cutler ME, Mcmorrow J, Pelz D, Tangki H, Boyd DS, Douglas L (2001) Mapping the biomass of Bornean tropical rain forest from remotely sensed data. Glob Ecol Biogeogr 10(4):379-387

Goetz S, Dubayah R (2011) Advances in remote sensing technology and implications for measuring and monitoring forest carbon stocks and change. Carbon Manag 2(3):231-244

Guo ZD, Fang JY, Pan Y, Birdsey R (2010) Inventory-based estimates of forest biomass carbon stocks in China: a comparison of three methods. For Ecol Manag 259(7):1225-1231

Guo QH, Liu J, Tao SL, Xue BL, Li L, Xu GC, Li WK, Wu FF, Li YM, Chen LH, Pang SX (2014) Perspectives and prospects of LiDAR in forest ecosystem monitoring and modeling. Chin Sci Bull 59(6):459-478. doi:10.1360/972013-592 (in Chinese)

Huang CH, Zhang ZY, Zhang WJ, Yang J (2012a) A review of overseas remote sensing monitoring methods for aboveground forest carbon sink. World For Res 25(6):20-26 (in Chinese)

Huang JW, Hu TX, Zhang ZH (2012b) The monitoring technology in Natural Forest Conservation Program. China Forestry Publishing, Beijing (in Chinese)

Huang KB, Pang Y, Shu QT, Fu T (2013) Aboveground forest biomass estimation using ICESat GLAS in Yunnan, China. J Remote Sens 17(1):165-179 (in Chinese)

Hyde P, Nelson R, Dan K, Levine E (2007) Exploring LiDARRaDAR synergy-Predicting aboveground biomass in a southwestern ponderosa pine forest using LiDAR, SAR and InSAR. Remote Sens Environ 106(1):28-38

IPCC (2003) Good practice guidance for land use, land-use change and forestry. IPCC/IGES, ISBN, Hayama, 4-88788-003-0

IPCC (2006) IPCC guidelines for national greenhouse gas inventory. IPCC/IGES, ISBN, Hayama, 4-88788-032-4

Kern JS (1994) Spatial patterns of soil organic carbon in the contiguous United States. Soil Sci Soc Am J 58(2):439-455

Krogh L, Noergaard A, Hermansen M, Greve MH, Balstroem T, Breuning-Madsen H (2003) Preliminary estimates of contemporary soil organic carbon stocks in Denmark using multiple datasets and four scaling-up methods. Agric Ecosyst Environ 96(1):19-28

Kurz WA, Dymond CC, White TM, Stinson G, Shaw CH, Rampley GJ, Smyth C, Simpson BN, Neilson ET, Trofymow JA, Metsaranta J, Apps MJ (2009) CBM-CFS3: a model of carbondynamics in forestry and land-use change implementing IPCC standards. Ecol Model 220(4):480-504

Li YC (2005) The grain for green project in China. China Forestry Publishing, Beijing (in Chinese)

Li TT, Ji HB, Sun YY, Luo JM, Jiang YB, Wang LX (2007) Advances in researches on soil organic carbon storages and affecting factors in China. J Cap Norm Univ (Nat Sci Ed) 28(1):93-97 (in Chinese)

Lim K, Treitz P, Wulder M, St-Onge B, Flood M (2003) LiDAR remote sensing of forest structure. Prog Phys Geogr 27(1):88-106

Liu J, Chen JM, Cihlar J, Park WM (1997) A process-based boreal ecosystem productivity simulator using remote sensing inputs. Remote Sens Environ 62(2):158-175

Liu SN, Zhou T, Shu Y, Dai M, Wei LY, Zhang X (2012) The estimating of spatial distribution of forest biomass in China based on remote sensing and downscaling techniques. Acta Ecol Sin 32(8):2320-2330 (in Chinese)

Luo YJ, Zhang XQ, Hou ZH, Yu PT, Zhu JH (2007) Biomass carbon accounting factors of Larix forests in China based on literature data. J Plant Ecol 31(6):1111-1118 (in Chinese)

Masera OR, Garza-Caligaris JF, Kanninen M, Karjalainen T, Liski J, Nabuurs GJ, Pussinen A, De Jong BHJ, Mohren GMJ (2003) Modeling carbon sequestration in afforestation, agroforestry and forest management projects: the CO2FIX V. 2 approach. Ecol Model 164(2):177-199

Ni J (2001) Carbon storage in terrestrial ecosystems of China: estimates at different spatial resolutions and their responses to climate change. Clim Chang 49(3):339-358

Pan Y, Birdsey RA, Fang JY, Houghton R, Kauppi PE, Kurz WA, Phillips OL, Shvidenko A, Lewis SL, Canadell JG, Ciais P, Jackson RB, Pacala SW, McGuire AD, Piao SL, Rautiainen A, Sitch S, Hayes D (2011) A large and persistent carbon sink in the world's forests. Science 333(6045):988-993

Parton WJ, Schimel DS, Cole CV, Ojima DS (1987) Analysis of factors controlling soil organic matter levels in Great Plains grasslands. Soil Sci Soc Am J 51(5):1173-1179

Parton WJ, Scurlock JMO, Ojima DS, Gilmanov TG, Scholes RJ, Schimel DS, Kirchner T, Menaut JC, Seastedt T, Moya EG, Kamnalrut A, Kinyamario JI (1993) Observations and modeling of biomass and soil organic matter dynamics for the grassland biome worldwide. Global Biogeochem Cycles 7(4):785-809

Peng CH, Liu JX, Dang QL, Apps MJ, Jiang H (2002) TRIPLEX: a generic hybrid model for predicting forest growth and carbon and nitrogen dynamics. Ecol Model 153(1):109-130

Post WM, Emanuel WR, Zinke PJ, Stangenberger AG (1982) Soil carbon pools and world life zones. Nature 298:156-159. doi:10. 1038/298156a0

Post WM, Peng TH, Emanuel WR, King AW, Dale VH, DeAngelis DL (1990) The global carbon cycle. Am Sci 78(4):310-326

Potter CS, Randerson JT, Field CB, Matson PA, Vitousek PM, Mooney HA, Klooster SA (1993) Terrestrial ecosystem production: a process model based on global satellite and surface data. Global Biogeochem Cycles 7(4):811-841

Richards G, Evans D (2000) Carbon Accounting Model for Forests (CAMFor) User Manual: Version 3.35. Australian Greenhouse Office

Running SW, Gower ST (1991) FOREST-BGC, a general model of forest ecosystem processes for regional applications. II. Dynamic carbon allocation and nitrogen budgets. Tree Physiol 9(1-2):147-160

Sader SA, Waide RB, Lawrence WT, Joyce AT (1989) Tropical forest biomass and successional age class relationships to a vegetation index derived from Landsat TM data. Remote Sens Environ 28:143-198

Schwartz D, Namri M (2002) Mapping the total organic carbon in the soils of the Congo. Glob Planet Chang 33(1):77-93

Sellers P (1985) Canopy reflectance, photosynthesis and transpiration. Int J Remote Sens 6(8):1335-1372

Smith JE, Heath LS (2001) Identifying influences on model uncertainty: an application using a forest carbon budget model. Environ Manag 27(2):253-267 
Smith B, Knorr W, Widlowski JL, Pinty B, Gobron N (2008) Combining remote sensing data with process modelling to monitor boreal conifer forest carbon balances. For Ecol Manag 255(12):3985-3994

Stinson G, Kurz WA, Smyth CE, Neilson ET, Dymond CC, Metsaranta JM, Boisvenue C, Rampley GJ, Li Q, White TM, Blain D (2011) An inventory-based analysis of Canada's managed forest carbon dynamics, 1990 to 2008. Glob Chang Biol 17(6):2227-2244

Tang SZ, Zhang HR, Xu H (2000) Study on establish and estimate and estimate method of compatible biomass model. Sci Silvae Sin 2000(S1):19-27 (in Chinese)

Tang XG, Liu DW, Wang ZM, Jiang MM, Dong ZY, Liu JY, Xu WM (2012) Estimation of forest aboveground biomass based on remote sensing data: a review. Chin J Ecol 31(5):1311-1318 (in Chinese)

Trotter C, Dymond J, Goulding C (1997) Estimation of timber volume in a coniferous plantation forest using Landsat TM. Int J Remote Sens 18(10):2209-2223

Wang SQ, Liu JY, Yu GR (2003) Error analysis of estimating terrestrial soil organic carbon storage in China. Chin J Appl Ecol 14(5):797-802 (in Chinese)

Wang D, Wang B, Niu X (2014) Forest carbon sequestration in China and its benefits. Scand J For Res 29(1):51-59

Wei XH, Blanco JA (2014) Significant Increase in ecosystem C can be achieved with sustainable forest management in subtropical plantation forests. PLoS One 9(2):e89688. doi:10.1371/journal. pone. 0089688

Wei YW, Zhou WM, Yu DP, Zhou L, Fang XM, Zhao W, Bao Y, Meng YY, Dai LM (2014) Carbon storage of forest vegetation under the Natural Forest Protection Program in Northeast China. Acta Ecol Sin. doi:10.5846/stxb201301240142 (in Chinese)

Yu DS, Shi XZ, Sun WX, Wang HJ, Liu QH, Zhao YC (2005) Estimation of China soil organic carbon storage and density based on 1:1000000 soil database. Chin J Appl Ecol 16(12):2279-2283 (in Chinese)

Yu GR, Fang HJ, Fu YL, Wang QF (2011) Research on carbon budget and carbon cycle of terrestrial ecosystems in regional scale: a review. Acta Ecol Sin 31(19):5449-5459 (in Chinese)

Yu DP, Wang XY, Yin Y, Zhan JY, Lewis BJ, Tian J, Bao Y, Zhou WM, Zhou L, Dai LM (2014) Estimates of forest biomass carbon storage in Liaoning Province of Northeast China: a review and assessment. PLoS One 9(2):e89572

Zhang J, Chu ZY, Ge Y, Zhou XL, Jiang H, Chang J, Peng CH, Zheng JW, Jiang B, Zhu JR, Yu SQ (2008) TRIPLEX model testing and application for predicting forest growth and biomass production in the subtropical forest zone of China's Zhejiang Province. Ecol Model 219(3):264-275

Zhi JJ, Jing CW, Zhang C, Wu JP, Ni ZH, Chen HJ, Xu J (2013) Estimation of soil organic carbon density and storage in Zhejiang Province of East China by using 1:50000 soil database. Chin J Appl Ecol 24(3):683-689 (in Chinese) 